\title{
Evaluating the Cost to Industry of Electricity Outages
}

\author{
Majid Hashemi \\ Department of Economics, Clemson University, Clemson, SC, USA \\ Email: majid.hashemi.86@gmail.com \\ Glenn P. Jenkins \\ Department of Economics, Queen's University, Kingston, Canada and \\ Eastern Mediterranean University, North Cyprus \\ Email: jenkins@econ.queensu.ca \\ Roop Jyoti \\ Vice-Chairman of Jyoti Group of Companies, Nepal \\ Aygul Ozbafli \\ Senior Financial Analyst, African Development Bank, Abidjan Cote d'ivoire \\ E-mail: aygul.ozbafli@gmail.com
}

\section{Development Discussion Paper: 2018 - 14}

\begin{abstract}
The unreliability of electricity supplies is a major cause of the high cost of manufacturing in developing countries. In this paper we propose a more accurate approach, the contribution method, to measure the cost imposed by power outages. We employ a rich, if not unique, set of data from the detailed operating accounts of three large manufacturing enterprises in Nepal. Estimating the true opportunity costs to the enterprises from lost production caused by power outages sheds light on the issue of cost measurement that is critical for the determination of the feasibility of mitigating measures. Furthermore, having such micro-based information on the value of lost load per kWh by firm or sector is critical for reducing the economic costs of planned outages by the electric utility.
\end{abstract}

Keywords: Electricity, Reliability, Outages, Opportunity Costs, Industry.

JEL Classifications: L94, Q41, Q48

Revised version published as: Hashemi, M.; Jenkins, G., P.; Jyoti, R.; Ozbafli, A. Evaluating the cost to industry of electricity outages. Energy Sources, Part B: Economics, Planning, and Policy Volume 13, 2018 - Issue 7 https://doi.org/10.1080/15567249.2018.1501122. 


\section{Introduction}

For many developing countries the unreliable supply of electricity is the norm rather than the exception. Power outages increase production costs, and raise the operating uncertainty that enterprises face. Production losses arise from loss in output, spoilage of in-process materials and even damage to machinery, all translating into financial losses. In a situation of uncertain power supply, an enterprise needs to know what strategies are available to address the problem, and then decide whether or not to make investments in facilities to minimize losses caused by the power problems $^{1}$. This decision would depend on the extent of the power outages and the consequent losses suffered by the enterprise. It, therefore, becomes imperative for many enterprises to find methods for dealing with power outages.

A number of previous studies have attempted to estimate the economic costs of unreliable electricity supplies, using a variety of techniques: the cost of back-up generators ${ }^{2}$ (Bental and Ravid 1982; Beenstock 1991; Matsukawa and Fujii 1994; Beenstock and Goldin 1997; Oseni and Pollitt 2015), the loss of production ${ }^{3}$ (Munasinghe and Gellerson 1979; Munasinghe, 1981; Pasha et al., 1989; Tishler 1993; De Nooij et al. 2007), the input-output method ${ }^{4}$ (Chen and Vella, 1994;

\footnotetext{
${ }^{1}$ It should be notified here that the objective of an enterprise is not how or whether to improve the reliability of the power supply system. In fact, the reliability is taken as an exogenous factor by enterprises. The objective, therefore, is to determine what can be done by the enterprise to address the problem once an outage occurs.

${ }^{2}$ In these studies the opportunity cost of unsupplied power is derived from the observation that firms hedge against power outages by investing in back-up generators. The marginal cost of unsupplied electricity is assumed to be the marginal cost of a kWh generated by a back-up generator. However, for industrial purposes backup generation may be imperfect substitute for utility supplied electricity. In other cases the cost of production using self-generation may be such that it is too expensive for the plant to operate competitively using back-up generation for more than short periods of outages.
}

${ }^{3}$ This method is based on the production-function approach. The consequences of outages are estimated through lost production (measured as gross value added for firms) or lost opportunity cost of time (for households).

${ }^{4}$ The Input-Output approach evaluates the impact of power outages on the loss in value added in the whole economy by recognizing the interdependence of all sectors of the economy. 
Ju et al., 2016), and the WTP method ${ }^{5}$ (Baarsma and Hop 2009; Morrison and Nalder 2009; Hensher et al. 2014; Ozbafli and Jenkins, 2015).

In the literature in electricity economics (Munasinghe, 1981; Pasha et al., 1989; Lehtonen and Lemstrom, 1995; De Nooij et al. 2007), the concept of value added has generally been employed while estimating the cost of power outages among different sectors in an economy. The value added by an enterprise is its revenue from selling a product minus its purchases of intermediate goods and services from other enterprises. The loss is measured by the total wage bill plus the cost of the capital services employed in the quantity of production that was lost due to the electricity outages. From the perspective of an on-going enterprise, the value-added approach may result in an incorrect estimate of the loss imposed by the lack of electricity reliability. One major drawback of this approach is that it does not take into consideration any savings in the direct labor cost per unit of output when a unit of output is not produced; and so, it overstates the cost. In Nepal when the electricity outage is long enough or the planned outage time is known, the firms can release the direct labor from work for the period and save the direct labor costs. At the same time the value added approach does not include the additional cost imposed through material wastage and the actual labor costs required to make the industrial processes ready after such an outage.

Thus, the main aim of this study is to improve the accuracy of evaluating the cost to industry of electricity outages by introducing the contribution approach. Contribution is the portion of the net sale revenues which goes towards meeting the overheads and towards creating the profits for the company. It is equivalent to short run producer surplus. A firm maximizes its profits by maximizing its contribution, and carries on conducting its business in the short run as long as the

\footnotetext{
${ }^{5}$ Stated Preference methods, including choice experiments and contingent evaluations, employ consumer surveys to obtain the set of consumer preferences required to estimate the willingness to pay (WTP) by households for more reliability.
} 
contribution is positive, even during circumstances when in the long run profits would be negative. When a unit of output is not produced due to a power outage, all components of the variable costs are saved. What is foregone is the opportunity cost in terms of the contribution which would have resulted and gone towards meeting the overheads and profits had that unit been produced ${ }^{6}$.

This approach can be used by an individual manufacturing enterprise to evaluate its true opportunity cost of power outages when evaluating the benefits and costs of investing in potential mitigating strategies. The significance of this method is highlighted for industrial electricity consumers where the impact of a power outage is different for each enterprise. This information on the value of lost load (VoLL) per kWh by enterprise is important also for the electric utility when it is forced to impose load shedding on its industrial customers (Praktiknjo, 2016). If there is a wide range of VoLL per kWh, it is far more efficient economically if the firms who have very low VoLLs have their electricity cut off first, while those who would face a high burden of losses are given an uninterrupted supply.

\section{Methodology}

There are expenses that have to be incurred irrespective of whether the plant is operating or not. The opportunity cost of forgone production during the period of the outage would be one of the primary losses. The extent of such a loss can be captured by estimating the lost contribution towards overhead and profits.

When an outage takes place, the loss in contribution gives us the true measure of the opportunity cost suffered by an enterprise. Other losses like material spoilage have to be added to obtain the total value of power outage cost. The equation for the contribution per unit of output is written as:

\footnotetext{
${ }^{6}$ In Nepal for long outages the employees representing direct labor are released from work and are not paid, hence, represent variable costs saved. At the same time the cost of both labor that is not released and paid plus any specialized labor that is involved in getting the plant back into working condition is added to the cost of the outage. The information used to calculate contribution come from the actual operating accounting systems of each of the firms.
} 


$$
\mathrm{b}=\mathrm{p}^{\text {net }}-\Sigma \mathrm{c}_{\mathrm{i}}^{\mathrm{m}}-\mathrm{c}^{1}-\mathrm{c}^{\mathrm{p}}-\mathrm{c}^{\mathrm{f}}-\mathrm{c}^{\mathrm{x}}
$$

Where $b$ is the contribution per unit of output, $\mathrm{p}^{\text {net }}$ is net revenue, $\mathrm{c}_{\mathrm{i}}^{\mathrm{m}}$ is the cost of direct material $\mathrm{i}$, per unit of output, $\mathrm{c}^{1}$ is the cost of direct labor per unit of output, $\mathrm{c}^{\mathrm{p}}$ is the cost of direct electricity per unit of output, $\mathrm{c}^{\mathrm{f}}$ is the cost of direct fuel per unit of output, and $\mathrm{c}^{\mathrm{x}}$ is the other direct costs per unit of output. $\mathrm{p}^{\text {net }}$ is in turn defined as,

$$
\mathrm{p}^{\text {net }}=\mathrm{p}-\mathrm{d}-\mathrm{m}-\mathrm{x}^{\text {selling }}
$$

Where $\mathrm{p}$ is the selling price per unit of output, $\mathrm{d}$ is the customer discounts per unit of output, $\mathrm{m}$ is the sales commissions per unit of output, and $\mathrm{x}^{\text {selling }}$ is direct sales expenses per unit of output. Alternatively (2) can be expressed as,

$$
\mathrm{p}^{\text {net }}=\mathrm{p}\left(1-\mathrm{d} \%-\mathrm{m} \%-\mathrm{x}^{\text {selling } \%}\right)
$$

Where $\mathrm{d} \%$ is the customer discounts, expressed as percentage of selling price, $\mathrm{m} \%$ is the sales commissions, expressed as percentage of selling price, and $\mathrm{x}^{\mathrm{selling}} \%$ is direct sales expenses, expressed as percentage of selling price. In contrast, if we were to express a relationship for value-added per unit of output, va, it would be:

$$
v a=p-\Sigma c_{i}^{m}-c^{p}-c^{f}-c^{x}
$$

We can see that this does not take into consideration the savings in direct labor that might result when a unit of output is not produced, hence overstating the cost of an interruption in production. After calculating the value of the contribution, we will determine the impact of power outages on the production process of the enterprise, and compute the quantity of output lost. We may also need to calculate other components of the outage cost such as material wastage and idle labor. We will then calculate the total value of loss suffered due to an outage.

Under the contribution method, the expression for the power outage cost, $\mathrm{C}^{\text {outage }}$ becomes: 


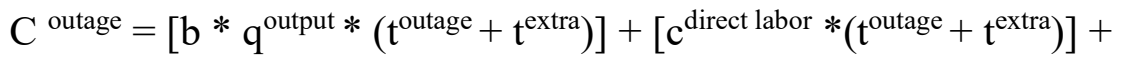

$$
\begin{aligned}
& {\left[\mathrm{Q}^{\text {spoilage } *}\left(\mathrm{c}^{\text {spoilage }}+\mathrm{c}_{\mathrm{s}}^{\text {labor }}+\mathrm{c}_{\mathrm{s}}^{\text {energy }}\right)\right]-\mathrm{S}^{\text {salvage }}}
\end{aligned}
$$

where, in addition to the definitions given above, $\mathrm{C}^{\text {outage }}$ is the total financial cost of the power outage, $\mathrm{q}^{\text {output }}$ is the quantity of output produced per unit of time, $\mathrm{t}^{\text {outage }}$ is the duration of the power outage, in hours, $\mathrm{t}^{\text {extra }}$ is the duration of extra time lost in a) restart up, b) removing spoiled materials-in-process etc., $\mathrm{c}^{\text {direct labor }}$ is the direct labor cost per hour, $\mathrm{Q}^{\text {spoilage }}$ is the units of spoiled materials-in-process, $\mathrm{c}^{\text {spoilage }}$ is the cost of spoiled materials-in-process per unit, $\mathrm{c}_{\mathrm{s}}^{\text {labor }}$ is the cost of labor to remove per unit of spoiled materials-in-process, $\mathrm{c}_{\mathrm{s}}{ }^{\text {energy }}$ is the cost of energy to remove per unit of spoiled materials-in-process, and $\mathrm{S}^{\text {salvage }}$ is the salvage value of spoiled materials-inprocess. If the enterprise is producing a number of products rather than a single one, the cost of the outage is the summation of the above expression across the whole range of products being produced.

In order to compare power outage costs across different enterprises, we need a numeraire which makes such comparisons meaningful. The outage cost per unit of power not supplied, in Rs per unit, is a number we can use to make comparisons across different types of enterprises. The amount of power not supplied can be expressed as:

$$
\mathrm{U}^{\text {outage }}=\left(\mathrm{U}^{\text {month }} / \mathrm{H}^{\text {month }}\right) *\left(\mathrm{t}^{\text {outage }}+\mathrm{t}^{\text {extra }}\right)
$$

where $\mathrm{U}^{\text {outage }}$ is the units $(\mathrm{kWh})$ of power not supplied during the power outage, $\mathrm{U}^{\text {month }}$ is the number of units of power consumed in a month, and $\mathrm{H}^{\text {month }}$ is the hours worked during the month. By dividing the actual number of units of power consumed in a month ( $U^{\text {month }}$ ) by the actual hours of production during that specific month $\left(\mathrm{H}^{\text {month }}\right)$, we can measure the electricity consumed per hour by the plant when running. If more power is consumed in a month ( $\left.U^{\text {month }}\right)$, it is generally because the plant has been running for more hours during that month $\left(\mathrm{H}^{\text {month }}\right)$. Hence, the amount of reduced consumption of electricity due to outages should be measured fairly accurately by 
equation 6 where the average hourly electricity consumption by the plant when working is multiplied by the amount of time the plant is not functioning due to the power outages.

The equation for the loss per unit of power not supplied is as given below:

$$
\mathrm{L}^{\text {outage }}=\mathrm{C}^{\text {outage }} / \mathrm{U}^{\text {outage }}
$$

where $L^{\text {outage }}$ is the cost of the power outage per unit of power not supplied.

A number of studies have attempted to estimate the cost of the power outage per $\mathrm{kWh}$ considering the cost imposed by the electricity outage on the entire value chain (Reichl et al., 2013; Praktiknjo, 2016). In Nepal, which is a small open economy, this might not be as great a concern as most of the industrial inputs are imported from India. In the short run, the variability of production is likely to cause the firm to incur some higher costs of managing input inventories due to the greater variability in their use due to the power outages. This cost, however, is expected to be small.

\section{Data}

This study uses data from a rich source of industrial information on each of the power outages that affected the production at a spinning mill, a steel re-rolling mill, and an oxygen factory in Nepal. All of the records are based on the actual accounting records of the firms hence enabling one to avoid many of the biases inherent in information obtained through customer surveys. We classify power outages into two types: power failures and load shedding. Power failures are unscheduled outages that occur without notice. Load shedding refers to outages that are planned ahead of time by Nepal Electricity Authority (NEA), and the firms are notified the exact time that the outage will occur.

The power outage data are obtained from two sources, Himal Iron \& Steel (P) Ltd. (Himal), a steel re-rolling mill that produces a variety of steel products, and Jyoti Spinning Mills Ltd. (JSM), both located in the central southern part of Nepal. Himal and JSM have methodically kept records of 
each occurrence of power failure - the time the power went off and came back - on a daily basis.

Similar to Himal, Himal Oxygen Ltd. (Oxygen) receives power from the same government owned

NEA substation. Therefore, Himal data on power outages is used for both Himal and Oxygen ${ }^{7}$.

Table 1: Frequency, Mean and Cumulative Duration of Power Failure per Year

\begin{tabular}{|c|c|c|c|c|c|c|}
\hline & & Year 1 & Year 2 & Year 3 & 3-year Average & Total \\
\hline \multirow{3}{*}{ Oxygen } & Count per year & 327 & 549 & 593 & 490 & 1,469 \\
\hline & Mean length of occurrence (hours per year) & 0.73 & 0.82 & 0.62 & 0.72 & \\
\hline & Duration (hours per year) & 238 & 449 & 370 & 352 & 1,057 \\
\hline \multirow{3}{*}{ Himal } & Count per year & 301 & 452 & 471 & 408 & 1,224 \\
\hline & Mean length of occurrence (hours per year) & 0.73 & 0.82 & 0.62 & 0.72 & \\
\hline & Duration (hours per year) & 219 & 370 & 294 & 294 & 882 \\
\hline \multirow{3}{*}{ JSM } & Count per year & 40 & 125 & 101 & 89 & 266 \\
\hline & Mean length of occurrence (hours per year) & 1.31 & 1.14 & 1.43 & 1.29 & \\
\hline & Duration (hours per year) & 52 & 142 & 143 & 112 & 337 \\
\hline
\end{tabular}

Source: Actual records of each enterprise

Table 1 and 2 show the annual frequency, mean and cumulative duration of power failure and load shedding for the three enterprises, respectively.

Table 2: Frequency, Mean and Cumulative Duration of Load Shedding per Year

\begin{tabular}{llccccc}
\hline \multirow{2}{*}{ Himal } & & Year 1 & Year 2 & Year 3 & 3-year Average & Total \\
\multirow{\&}{*}{ Oxygen } & Count per year & 195 & 245 & 92 & 177 & 532 \\
& Mean length of occurrence (hours per year) & 3.00 & 1.90 & 1.91 & 2.27 & 409 \\
& Cumulative duration (hours per year) & 585 & 465 & 175 & & 1,226 \\
\hline & & Year 1 & Year 2 & Year 3 & 3-year Average & Total \\
\multirow{3}{*}{ JSM } & Count per year & 108 & 203 & 92 & 134 & 403 \\
& Mean length of occurrence (hours per year) & 2.40 & 1.98 & 2.00 & 2.13 & 282 \\
& Cumulative duration (hours per year) & 260 & 401 & 184 & 245 \\
\hline
\end{tabular}

\footnotetext{
7 It should be noted here that since Oxygen operates twenty-four hours a day, seven days a week, it suffers from more outages than Himal. At Himal, however, the production operations are performed only in two shifts of 8 hours each, or for 16 hours a day, and that too, for only six days in the week. The operating hours are from 6 AM to 10 PM, 6 AM to 2 PM for the first shift and from 2 PM to 10 PM for the second shift. Therefore, the frequency of the power failures for Himal, shown in Table 1, is adjusted by excluding those power outages occurred between 10 PM and 6 AM. Furthermore, the power failures in 88 non-working days in the year are also removed.
} 


\section{Analysis}

\subsection{Production time lost}

The impact of a power failure on production time lost can be much longer than the duration of time of the power failure itself. So, in order to calculate total production time lost, one needs to add the extra time needed to restart the production after a power failure to the duration of that power failure. Based on a detailed record of actual and individual incidents of power failure and restarting time available for the three enterprises, we can calculate the ratio of the of difference between the production restarting duration minus the power failure duration over the duration of the power failure. This ratio is different for each enterprise due to their different nature of activities. Accordingly, the ratio amounts to $0.94,1.1$ and 2.39 for Himal, JSM and Oxygen, respectively. In other words, a power failure of 1 hour would result in an actual production time loss of 1.94, 2.1 and 3.39 hours for Himal, JSM and Oxygen, respectively.

\subsection{Contribution values}

During an outage, an enterprise has two options: suspend the production till the power is restored; or, invest in mitigating equipment (e.g., installing generators) and produce as planned. Making a decision about whether to invest or not requires a careful appraisal of mitigating strategies using cost-benefit analysis. The first step is to quantify the value of forgone production.

The sales revenue, the discounts and the commissions can be obtained from the income statement of the enterprises. The quantity of the products sold in that particular year is also known. Dividing the sales revenue by the quantity sold, one can find the selling price per unit. Similarly, the per unit value of the discounts and commissions, and the net selling price are calculated.

Next, one needs to find the direct costs of production per unit of the product. In this case, it is the quantity of goods produced that is needed. From these numbers, one can estimate the components 
of direct material (raw materials), direct labor, direct electricity, and other direct costs such as packing. These values were estimated from the detailed operating accounts for each of the firms studied. Table 3 shows the cost estimates of forgone production per unit of output due to outages for each enterprise in Year 1, using both contribution and value added approach. JSM incurs a contribution loss per unit of forgone production equal to 35 percent of its net sales revenues. Himal and Oxygen also suffer from such contribution losses of 18 and 43 percent, respectively. Using the value-added approach, however, these losses are overstated by a degree of 11,18 and 51 percent in case of JSM, Himal and Oxygen, respectively. These differences exist since the valueadded approach provides a measure of gross value of lost production while the contribution approach yields the net value. An enterprise has to suspend the production during power outages. If net selling revenues that could have been generated during outages are sufficient to cover variable operating costs and the costs of re-starting production from its idle mode, investment in mitigation strategies may become economically viable.

Table 3: Value of forgone production due to outages per unit of output in Year 1 (2016 prices)

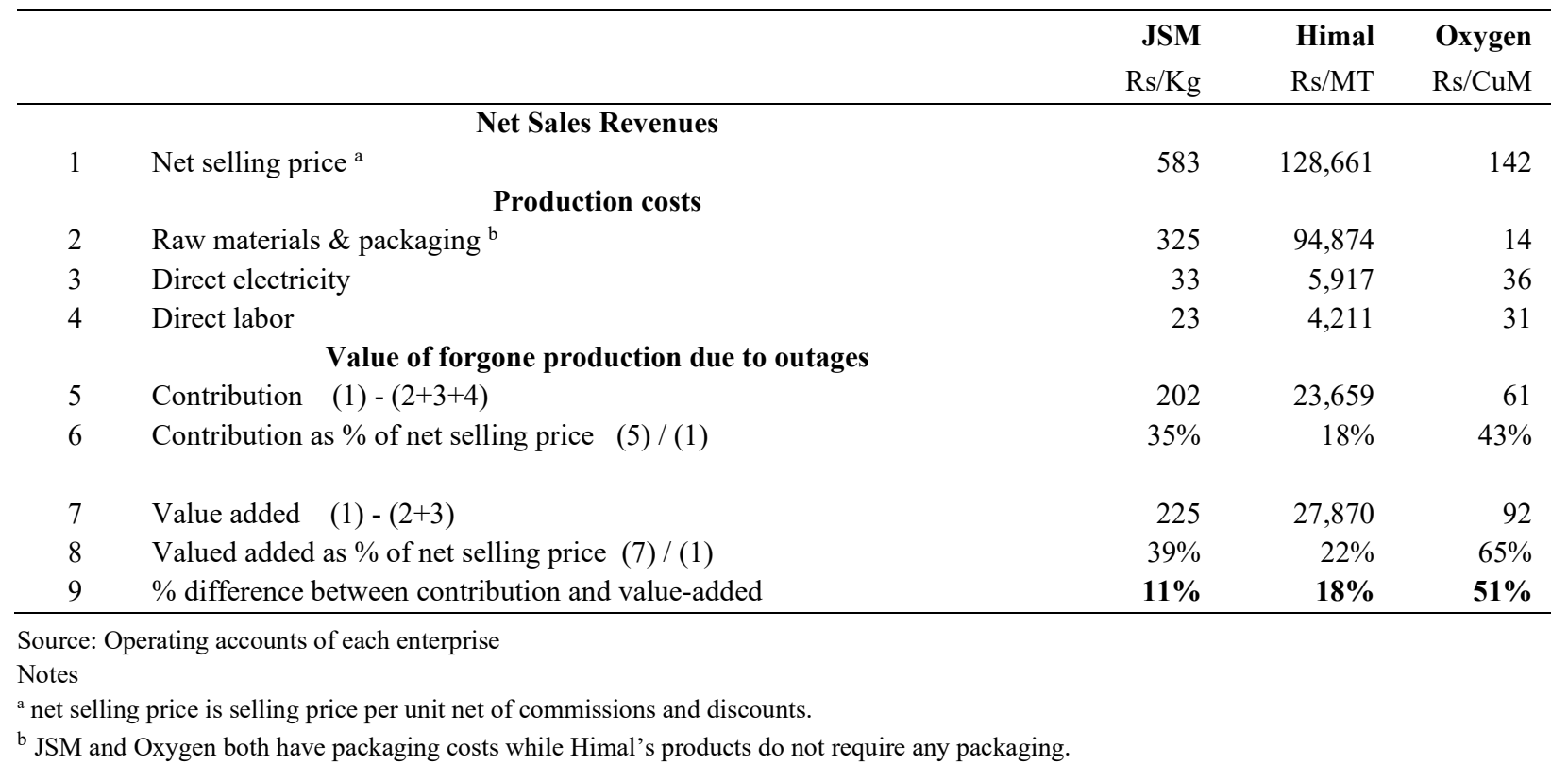




\subsection{Evaluating the cost of power failures}

Using the cumulative duration of power failures from Table 1 and the ratio of production restarting time to power failure of 1.94 for Himal, the total actual production time lost from the power failures is calculated (Table 4 row 1). For Himal, the average production value has been obtained from the production records and so have been the values for man-hour rate and average power consumption during the year. The total production lost, is obtained by multiplying the total actual production time lost by the average production rate. The total contribution loss is the product of the total production lost and the contribution value, taken from row 5 in Table 3. Similarly, the total manhour loss is arrived at by multiplying the total actual production time lost, by the man-hour rate. At Himal, power failures also result in wastage of the materials-in-process and the fuel oil, and these have to be included. Himal kept records of the quantities of this wastage. Records are also available on the selling price of the finished products and the purchase price of furnace oil in the respective years. From these, the value of the wastage is calculated. The furnace oil waste is a product of the quantity and the price. In the case of material waste (misroll), an estimated cost equal to $50 \%$ of the regular selling price of the final product gives us a reasonable approximation of the value of the input materials wasted. The total loss from power failures at Himal is the sum of the total contribution loss, the total man-hour loss, the material waste (see equation 5).

The next step is to calculate the loss per $\mathrm{kWh}$ not supplied. First, the unit $(\mathrm{kWh})$ of power not supplied during power failures is estimated. This is obtained by multiplying the total actual production time lost, in hours by the average rate of power consumption, in $\mathrm{kWh}$ per hour. Finally, 
the loss in Rs per kWh unsupplied is obtained by dividing the total loss from power failure, in Rs, by the power not supplied, in $\mathrm{kWh}$.

As shown in Table 4, in the case of Oxygen, the cost is estimated as $0.34 \mathrm{US} \$ / \mathrm{kWh}$ (2016 prices). We repeat the same evaluations for JSM and Himal and find losses of $0.57 \mathrm{US} \$ / \mathrm{kWh}$ and 1.64 $\mathrm{US} \$ / \mathrm{kWh}$ for them, respectively.

Table 4: Loss per kWh Unsupplied in Year 1 (2016 prices)

\begin{tabular}{|c|c|c|c|c|c|}
\hline & Item & Units & Oxygen & JSM & Himal \\
\hline 1 & Total Production Time Lost ${ }^{a}$ & hours & 806 & 110 & 425 \\
\hline 2 & Average Production & unit of output / hour & 28.35 & 264 & 2.57 \\
\hline 3 & Total Quantity of Production Loss ${ }^{b}$ & unit of output & 22,854 & 28,946 & 1,092 \\
\hline 4 & Total Contribution Loss ${ }^{c}$ & Rs & $1,390,674$ & $5,847,144$ & $25,841,543$ \\
\hline 5 & Idle Labor Rate ${ }^{\mathrm{d}}$ & Rs/hour & 617 & 6,927 & 1,615 \\
\hline 6 & Total Man-hours Lost ${ }^{\mathrm{e}}$ & Rs & 497,390 & 759,338 & 686,375 \\
\hline 7 & Material Waste $^{\mathrm{f}}$ & Rs & - & - & $1,592,602$ \\
\hline 9 & Total Loss during Power Outages ${ }^{g}$ & Rs & $1,888,063$ & $6,606,485$ & $28,120,520$ \\
\hline 10 & Average Power Consumed & $\mathrm{kWh} /$ hour & 64 & 1,008 & 385 \\
\hline 11 & Power not Supplied ${ }^{\mathrm{h}}$ & $\mathrm{kWh}$ & 51,956 & 110,508 & 163,434 \\
\hline 12 & Loss per kWh Unsupplied ${ }^{\text {i }}$ & $\mathbf{R s} / \mathbf{k W h}$ & 36 & 60 & 172 \\
\hline 13 & Loss per kWh Unsupplied $^{\text {j }}$ & $\mathbf{U S \$ / \mathbf { k W h }}$ & 0.34 & 0.57 & 1.64 \\
\hline \multicolumn{6}{|c|}{ Notes } \\
\hline \multicolumn{6}{|c|}{$\begin{array}{l}\text { a Total production time lost equals to the total duration of outages in a year (from Table } 1 \text { ) multiplied by the ratio of the production restarting } \\
\text { duration over the power failure duration. The ratio is } 3.39,2.1 \text {, and } 1.94 \text { for Oxygen, JSM and Himal, respectively. }\end{array}$} \\
\hline \multicolumn{6}{|c|}{ b row 1 multiplied by row 2} \\
\hline \multicolumn{6}{|c|}{${ }^{c}$ contribution loss per unit of output (row 5, Table 3 ) multiplied by row 3} \\
\hline \multicolumn{6}{|c|}{${ }^{\mathrm{d}}$ Idle labor rate is determined by dividing the total expenditure on direct labor by the total number of hours worked, in a particular year. } \\
\hline \multicolumn{6}{|c|}{ e row 1 multiplied by row 5} \\
\hline \multicolumn{6}{|c|}{$\begin{array}{l}\mathrm{f} \text { Tangible losses are substantial only in case of Himal. The cost reflects the value of mis-rolled material (net of salvage value) and the extra fuel } \\
\text { burned during power failures. }\end{array}$} \\
\hline \multicolumn{6}{|c|}{${ }^{\mathrm{g}}$ For Oxygen and JSM: row 4 + row 6 ; for Himal: row 4 + row 6 + row 7.} \\
\hline \multicolumn{6}{|c|}{${ }^{\mathrm{h}}$ row 1 multiplied by row 10} \\
\hline \multicolumn{6}{|c|}{${ }^{\mathrm{i}}$ row 9 divided by row 11} \\
\hline & & & & & \\
\hline
\end{tabular}

We saw in Table 3 that Oxygen is the most energy-intensive enterprise among the three with its direct electricity expenditure amounting to 25 percent of its net selling revenue (36/142), per unit of output, compared to 6 and 5 percent for JSM and Himal, respectively. According to Table 4, however, Oxygen incurs an opportunity cost of $0.34 \mathrm{US} \$ / \mathrm{kWh}$ compared to Himal, the least energy-intensive enterprise, which has the highest opportunity cost of power outages. This can be explained by the fact that when an enterprise uses less electricity in its production operation, then an interruption in the supply of that small quantity of electricity prevents the utilization of the other 
inputs and causes loss. For instance, if a tiny amount of electricity is used for turning on a switch to keep the production going and if that electricity is not supplied then clearly the opportunity cost of that quantity of power would be very substantial.

\subsection{Evaluating the cost of load shedding}

In order to calculate the cost of load shedding, we need to replicate the same steps as we did in case of power failures while considering the fact that because of the planned nature of load shedding, the extra production time lost is relatively small as compared to power failures. Hence, there is no loss in terms of extra production time and the actual production time loss is equal to the duration of load shedding itself. Due to the production process, however, the situation at Oxygen is different. The interruption of electricity, whether planned or unplanned, has a similar effect on extending the time of production loss beyond the period of the power outage. We have, therefore, to take into account the extra time lost due as in the case of power failures. The remaining calculations are identical to the case of power failures.

The results in Table 5 point out the wide range of opportunity costs that electricity unreliability is imposing on the three Nepalese manufacturing enterprises in our sample. It can be inferred from these results that the impact of a power outage is different for each enterprise in a given year. Also, even in the same enterprise, the impact of a power outage will not be the same at all times. 
Table 5: Opportunity Costs of Power Failures and Load Shedding, US\$/kWh, 2016 prices

\begin{tabular}{|c|c|c|c|c|c|}
\hline & $\begin{array}{c}\text { Year } 1 \\
\text { (1) }\end{array}$ & $\begin{array}{c}\text { Year } 2 \\
(2)\end{array}$ & $\begin{array}{c}\text { Year } 3 \\
\text { (3) }\end{array}$ & $\begin{array}{c}\text { 3-year average } \\
\text { (4) }\end{array}$ & $\begin{array}{c}\text { 3-year average as \% of average power } \\
\text { tariff } \\
(4) /(0.08 \mathrm{US} \$ / \mathrm{kWh})\end{array}$ \\
\hline \multicolumn{6}{|l|}{ Power Failure } \\
\hline Himal & 1.64 & 1.98 & 2.56 & 2.06 & 25.75 \\
\hline JSM & 0.57 & 0.42 & 0.71 & 0.57 & 7.12 \\
\hline Oxygen & 0.34 & 0.47 & 0.28 & 0.36 & 4.50 \\
\hline \multicolumn{6}{|l|}{ Load Shedding } \\
\hline Himal & 1.61 & 2.05 & 2.88 & 2.18 & 27.25 \\
\hline JSM & 0.57 & 0.42 & 0.71 & 0.57 & 7.12 \\
\hline Oxygen & 0.34 & 0.47 & 0.28 & 0.36 & 4.50 \\
\hline
\end{tabular}

Loss per kWh unsupplied is a measure of the opportunity cost of marginal power supply for an enterprise. In other words, this would be the willingness to pay value for the supply of power which would prevent an outage. Hence, it is worthwhile comparing the loss per kWh unsupplied to an average power tariff paid to NEA by these enterprises. We can see that even for Oxygen with the lowest three-year average cost of power failure (0.36 US\$/kwh), the opportunity cost of per kwh unsupplied is 4.5 times more than the average tariff of $0.08 \mathrm{US} \$ / \mathrm{kWh}$ charged by NEA for industrial consumers (NEA, 2016). This denotes the premium that the enterprise would be willing to pay over the existing tariff for a reliable electricity supply.

Table 6 summarizes the findings of various studies for the willingness to pay per hour unserved. We have adjusted each of the willingness to pay values estimated by other studies to bring them into 2016 US\$ per kWh of unserved electricity. The comparative results are interesting as the finding of our paper which is very much micro analysis based is quite consistent in terms of the range of estimated values of the WTP with the only other study on Nepal (Billinton and Pandey, 1999) that was focused on the WTP of households. In general the estimated losses from these three very different types of industrial firms (in terms of electricity intensiveness and damage created 
from outages) is somewhat lower than other studies that have used a more aggregated econometric approach to the measurement of the WTP for industrial sectors.

Table 6: Willingness to pay (USD per hour unserved, 2016 prices)

\begin{tabular}{|c|c|c|c|c|}
\hline Country & Study & Estimation Technique & $\begin{array}{l}\text { Consumer } \\
\text { Type }\end{array}$ & $\begin{array}{c}\text { WTP US\$ per kWh } \\
\text { unserved }\end{array}$ \\
\hline Austria & Reichl et al. (2013) & $\begin{array}{l}\text { Contingent valuation method and } \\
\text { value added approach }\end{array}$ & $\begin{array}{l}\text { Household } \\
\text { and Non- } \\
\text { household }\end{array}$ & $3.2-21.2$ \\
\hline Brazil & Munasinghe (1980) & Value of lost leisure & Household & 5.32 \\
\hline Sweden & $\begin{array}{l}\text { Carlsson and Martinsson (2007, } \\
\text { 2008) }\end{array}$ & Choice experiment & Household & $0.32-3.2$ \\
\hline Nepal & Billinton and Pandey (1999) & Consumer survey & Household & $0.11-1.28$ \\
\hline North Cyprus & Ozbafli and Jenkins (2016) & Choice experiment & Household & $0.27-1.03$ \\
\hline Netherlands & De Nooij et al. (2007) & Value added approach & Industrial & 2.32 \\
\hline Ghana & Oseni and Pollitt (2015) & Cost of back-up generators & Industrial & $1.75-3.28$ \\
\hline Nigeria & Oseni and Pollitt (2015) & Cost of back-up generators & Industrial & $2.02-2.28$ \\
\hline South Africa & Oseni and Pollitt (2015) & Cost of back-up generators & Industrial & $5.00-10.56$ \\
\hline Nepal & This study & Contribution approach & Industrial & $0.28-2.88$ \\
\hline
\end{tabular}

Our analysis provides insights for both the public utility and the enterprise itself. It is helpful for the public utility in the sense that the willingness to pay values represent the premium the public utility can charge to the consumer if it could provide uninterrupted electricity supply. It also represents the loss to the economy from an electricity outage for a particular firm. From the enterprises' perspective, this can be the foundation of the cost-benefit analysis for total replacement of power supply from the public utility to self-generation, avoiding the residual losses.

\section{Conclusion}

The uncertainties in power supply in pose serious threats to the economic well-being of the enterprises in that country and it becomes imperative for many enterprises to find methods for dealing with power outages in a situation of uncertain power supply. The first task, therefore, for an enterprise is to identify what strategies are available to address the problem. This decision would depend on the extent of the power outages and the consequent losses suffered by the enterprise. Estimating the opportunity costs to the enterprises from lost production from power outages shed 
some light on the issue of cost measurement and would be helpful to evaluate the feasibility of mitigating measures. Loss per kWh not supplied is a measure of the opportunity cost of marginal power supply for an enterprise. In other words, this would be the willingness to pay value for the supply of power which would prevent an outage. These estimates of the cost of electricity outages provide guidance to electric utilities and planners of the economic value of improving electricity service reliability.

Using the contribution approach for three Nepalese enterprises as case studies, we found that electricity unreliability imposes a wide range of costs to each enterprise, from US $\$ 0.28 / \mathrm{kWh}$ up to US $\$ 2.88 / \mathrm{kWh}$ of electricity not supplied. Hence, after identifying the possible options available for mitigating the problem, the approach used in this paper can be employed to examine the measures to determine those that are financially or economically feasible. In addition, having such micro-based information on the cost of loss of service per $\mathrm{kWh}$ is critical for reducing the economic costs of planned outages by the electric utility. With this information, they would be in a better position to prioritize the firms in terms of load shedding. Those with relatively low costs of loss of service per kWh should have their electricity service interrupted first while those with a high cost of loss of service per kWh would be provided service or interrupted for relatively short periods of time. 


\section{REFERENCES}

Baarsma, B.E. and Hop, J.P., 2009. Pricing power outages in the Netherlands. Energy, 34(9), pp.1378-1386.

Beenstock, M., 1991. Generators and the cost of electricity outages. Energy Economics, 13(4), pp.283-289.

Beenstock, M., Goldin, E. and Haitovsky, Y., 1997. The cost of power outages in the business and public sectors in Israel: revealed preference vs. subjective valuation. The Energy Journal, pp.39-61.

Bental, B. and Ravid, S.A., 1982. A simple method for evaluating the marginal cost of unsupplied electricity. The Bell Journal of Economics, pp.249-253.

Billinton, R., and Pandey, M., 1999. Reliability worth assessment in a developing country residential survey results, IEEE Transactions and Power Systems, 14 (4), pp. 1226-1231.

Carlsson, F., and Martinsson, P., 2007.Willingness to pay among Swedish households to avoid power outages - a random parameter Tobit model approach. Energy Journal, 28 (1), pp. 75-90.

Carlsson, F., and Martinsson, P., 2008. Does it matter when a power outage occurs? A choice experiment study on the willingness to pay to avoid power outages. Energy Economics, 30 (3), pp. 1232-1245.

Chen, C.Y. and Vella, A., 1994. Estimating the economic costs of electricity shortages using inputoutput analysis: the case of Taiwan. Applied economics, 26(11), pp.1061-1069.

De Nooij, M., Koopmans, C., and Bijvoet, C. (2007). The value of supply security: The costs of power interruptions: Economic input for damage reduction and investment in networks. Energy Economics, 29(2), 277-295.

Hensher, D.A., Shore, N. and Train, K., 2014. Willingness to pay for residential electricity supply quality and reliability. Applied Energy, 115, pp.280-292.

Ju, H.C., Yoo, S.H. and Kwak, S.J., 2016. The electricity shortage cost in Korea: An input-output analysis. Energy Sources, Part B: Economics, Planning, and Policy, 11(1), pp.58-64.

Lehtonen, M. and Lemstrom, B., 1995, November. Comparison of the methods for assessing the customers' outage costs. In Energy Management and Power Delivery, 1995. Proceedings of EMPD'95., 1995 International Conference on (Vol. 1, pp. 1-6). IEEE.

Matsukawa, I. and Fujii, Y., 1994. Customer preferences for reliable power supply: using data on actual choices of back-up equipment. The Review of Economics and Statistics, pp.434-446.

Morrison, M. and Nalder, C., 2009. Willingness to pay for improved quality of electricity supply across business type and location. The Energy Journal, pp.117-133. 
Munasinghe, M., 1980. Costs incurred by residential electricity consumers due to power failures. Journal of Consumer Research, 6 (4), pp. 361-369.

Munasinghe, M., 1981. Optimal electricity supply: reliability, pricing and system planning. Energy Economics, 3(3), pp.140-152.

Munasinghe, M. and Gellerson, M., 1979. Economic criteria for optimizing power system reliability levels. The Bell Journal of Economics, pp.353-365.

Nepal Electricity Authority (NEA) 2016. Annual report 2016. http://www.nea.org.np/annualreport (accessed January 18, 2017).

Oseni, M. O., and Pollitt, M. G., 2015. A firm-level analysis of outage loss differentials and selfgeneration: Evidence from African business enterprises. Energy Economics, 52, pp. 277286 .

Ozbafli, A. and Jenkins, G.P., 2015. The willingness to pay by households for improved reliability of electricity service in North Cyprus. Energy Policy, 87, pp. 359-369.

Ozbafli, A., and Jenkins, G. P., 2016. Estimating the willingness to pay for reliable electricity supply: A choice experiment study. Energy Economics, 56, pp. 443-452.

Pasha, H.A., Ghaus, A. and Malik, S., 1989. The economic cost of power outages in the industrial sector of Pakistan. Energy Economics, 11(4), pp.301-318.

Praktiknjo, A., 2016. The value of lost load for sectoral load shedding measures: The German case with 51 sectors. Energies, 9(2), pp. 116.

Reichl, J., Schmidthaler, M., and Schneider, F., 2013. The value of supply security: The costs of power outages to Austrian households, firms and the public sector. Energy Economics, 36, pp. 256-261.

Tishler, A., 1993. Optimal production with uncertain interruptions in the supply of electricity: estimation of electricity outage costs. European Economic Review, 37(6), pp. 1259-1274. 